\title{
Muscular microsporidian infection in Arctic char Salvelinus alpinus from two lakes in Nunavik, Quebec, Canada
}

\author{
Marion Jalenques ${ }^{1}$, Justin Sanders ${ }^{2}$, Lilian $\operatorname{Tran}^{3}{ }^{,}$Laurie Beaupré ${ }^{4}$, Michael Kent ${ }^{2}$, \\ Stéphane Lair ${ }^{1, *}$
}

\begin{abstract}
${ }^{1}$ Centre québécois sur la santé des animaux sauvages / Canadian Wildlife Health Cooperative, Faculté de médecine vétérinaire, Université de Montréal, St. Hyacinthe, Quebec J2S 2M2, Canada

${ }^{2}$ Carlson College of Veterinary Medicine, Oregon State University, Corvallis, OR 97331, USA

${ }^{3}$ Makivik Corporation, Kuujjuaq, Quebec J0M 1C0, Canada
\end{abstract}

${ }^{4}$ Direction de la gestion de la faune du Nord-du-Québec Ministère des Forêts, de la Faune et des Parcs, Chibougamau, Quebec G8P 2Z3, Canada

\begin{abstract}
Arctic char Salvelinus alpinus is an important cultural and subsistence resource for Inuit communities. Muscular infections by microsporidia were diagnosed for the first time in Arctic char originating from 2 different lakes in Nunavik (Quebec, Canada). The consumption of these infected fish was associated with digestive tract disorders in people. To better characterize microsporidiosis in these char populations, a cross-sectional study was conducted on 91 fish. The microsporidium was classified as a member of the Microsporidium collective genus by morphological evaluation and phylogenetic analysis using small subunit ribosomal DNA sequence data. The presence and severity of infection were determined histologically. Microsporidian infection occurred in $61 \%$ of the fish (56/91) and was significantly associated with an increase in their age, length and weight. The severity of infection (percentage of muscle area affected by microsporidia) was mild in most cases ( $<1 \%$ of the total muscle area). Based on multiple linear regression modeling, the severity of infection was significantly greater in females and negatively correlated with the body condition. Despite a high prevalence, the low pathogenicity of the infection suggests that microsporidiosis has little impact on these char populations. Moreover, since digestive-tract disorders following ingestion of fish infected by microsporidia have never been reported in humans, it seems unlikely that it was responsible for the reported clinical signs. Anisakid larvae are occasionally observed in these char populations. Digestive-tract infection associated with ingestion of these larvae should thus be considered as a potential differential diagnosis in these Inuit communities.
\end{abstract}

KEY WORDS: Microsporidia - Salvelinus alpinus - Arctic char - Myositis - Nunavik - Anisakis · Zoonosis

\section{INTRODUCTION}

Arctic char Salvelinus alpinus, teleosts from the family Salmonidae, are found in lakes, rivers and coastal saltwater across northern North America,

\footnotetext{
${ }^{*}$ Corresponding author: stephane.lair@umontreal.ca
}

where they occur as both anadromous and resident freshwater (landlocked) populations (Fisheries and Oceans Canada 2014, Kuhnlein \& Humphries 2017, Martyniuk et al. 2020). This fish species is an important part of the traditional Inuit diet and is consumed 
raw, boiled, dried or fermented in local communities (Kuhnlein \& Humphries 2017). Muscular infections by microsporidia (microsporidiosis) have been opportunistically documented in Arctic char from Lake Duquet located near Salluit, Nunavik, Quebec, Canada (Wildlife Health Intelligence Platform, Canadian Wildlife Health Cooperative). These fish, which were harvested by fishermen from local communities, were submitted in response to the occurrence of various symptoms including vomiting and oral-tingling sensations, following consumption of raw char flesh. Similar symptoms have also been reported in people fishing in the nearby Lake Françoys-Malherbe. These occurrences took place in spring (April) or summer (September). The prevalence of the parasite, its significance for the health of this population of fish and its zoonotic potential are unknown.

Microsporidia are obligate sporulating intracellular parasites related to Fungi. This group includes over 1000 species able to infect a broad spectrum of hosts, from unicellular organisms to vertebrates, including humans (Lom 2002, Stentiford et al. 2016). Although infections by these organisms are relatively common in fish, most species are poorly described and new species are regularly discovered. Species in the genera Heterosporis, Pleistophora, Kabatana, Tetramicra, Myosporidium and in the collective group Microsporidium are known to infect the skeletal muscles of susceptible teleost fish hosts (Kent et al. 1999, 2014, Lom 2002, Ahonen 2017). It is believed that most fish microsporidia complete their life cycle within a single host, through horizontal transmission by ingestion of infected tissues or spores in the water. In addition, some species of microsporidia include vertical (intraovum) transmission in their life cycles (e.g. Pseudoloma neurophilia: Sanders \& Kent 2013; Ovipleistophora ovariae: Kent et al. 2014). With horizontal transmission, microsporidia that infect muscle enter the intestinal wall and reach the muscles where they multiply (merogony) and produce new spores (sporogony) that will be released into the tissues or the external environment (Lom 2002, Miller 2009, Kent et al. 2014). The infection may cause significant muscle damage and contribute to indirect fish mortality due to debilitation or increased susceptibility to predation (Sprengel \& Lüchtenberg 1991, Figueras et al. 1992, Miller 2009, Kent et al. 2014, Phelps et al. 2015). In addition, heavy infections of the muscle often cause macroscopic changes that diminish the value of the fish for human consumption (Tomamichel et al. 2018).

Here we describe a microsporidian infection in Arctic char in 2 lakes in Nunavik. The objectives of this study were to (1) determine the prevalence of microsporidiosis in Arctic char populations from Lakes Duquet and Françoys-Malherbe, (2) characterize the lesions caused by this organism, (3) evaluate the association between the infection and fish characteristics such as body condition and (4) elucidate the taxonomic status of this novel infection. Potential causes of the symptoms reported by Inuit following the consumption of raw fish will also be discussed.

\section{MATERIALS AND METHODS}

\subsection{Study area and sampling}

This project was realized from 1-7 May 2018, in collaboration with regional stakeholders including the Makivik Corporation, the Ministère des Forêts, de la Faune et des Parc (MFFP) and Raglan Mine. Fish were obtained from Lake Duquet (Tasialujjuaq) $\left(62^{\circ} 03^{\prime} 18^{\prime \prime} \mathrm{N}, 7^{\circ} 31^{\prime} 51^{\prime \prime} \mathrm{W}\right)$ and Lake FrançoysMalherbe (Pangaligiak) (62 $\left.00^{\circ} 06^{\prime \prime} \mathrm{N}, 74^{\circ} 15^{\prime} 25^{\prime \prime} \mathrm{W}\right)$. These lakes, which are $7.7 \times 1 \mathrm{~km}$ and $25 \times 1-1.5 \mathrm{~km}$ in size, respectively, are located in proximity to the community of Salluit, Nunavik (Quebec, Canada) and used by the local fishermen. Both freshwater lakes outflow into Deception Bay (Hudson Strait) via the Deception River. Even if anadromous and landlocked char populations inhabit these lakes, the present study involves char from the anadromous population only. Anadromous Arctic char at Deception Bay only feed out at sea, where they prey opportunistically on zooplankton and pelagic and benthic fishes (Martyniuk et al. 2020).

For this study, sampling took place in the spring when anadromous Arctic char are fasting (Martyniuk et al. 2020). A total of 91 Arctic char, 61 from Lake Duquet and 30 from Lake Françoys-Malherbe, were captured respectively by gill nets and fishing lines set under the ice cover as part of planned subsistence fishing by local elders. Once captured, the fish were stunned, pithed and stored in an isolated cooler to prevent them from freezing. Morphological measurements and macroscopic examination were performed on the day of capture. Sex, age (otolith analysis; Campana \& Thorrold 2001), fork length, weight, and Fulton's condition factor $K$ were determined for each fish. Fulton's condition factor was defined by $K=100 \times$ total weight $/$ (fork length) ${ }^{3}$ with the weight in grams and the fork length in centimeters (Ricker 1975). Characteristics of the sampled fish are presented in Table 1. A complete post-mortem examination, including thorough inspections of filleted mus- 
Table 1. Characteristics of the Arctic char Salvelinus alpinus sampled in this study. Arctic char were captured respectively by gill nets and jig fishing lines set under the ice cover from Lake Duquet and Lake Françoys-Malherbe, located near the community of Salluit, Nunavik, Canada. Fulton's condition factor defined as: $K=100 \times$ total weight $/\left(\right.$ fork length) ${ }^{3}$, with total weight in grams and fork length in centimeters

\begin{tabular}{|c|c|c|c|}
\hline & Duquet (n = 61) & Françoys-Malherbe $(\mathrm{n}=30)$ & Total $(\mathrm{n}=91)$ \\
\hline \multicolumn{4}{|l|}{ Sex } \\
\hline Female & 36 & 22 & $58(64 \%)$ \\
\hline Male & 25 & 8 & $33(36 \%)$ \\
\hline Age $(y r)^{a}$ & $10 \pm 1(7-15)$ & $9 \pm 2(5-14)$ & $10 \pm 2(5-15)$ \\
\hline Fork length $(\mathrm{cm})^{\mathrm{a}}$ & $46.1 \pm 12.9(42.9-66.3)$ & $51.6 \pm 6.3(19.5-70.4)$ & $49.8 \pm 9.3(19.5-70.4)$ \\
\hline Total weight $(g)^{a}$ & $1449 \pm 583(786-3108)$ & $1125 \pm 763(63-2522)$ & $1341 \pm 662(63-3108)$ \\
\hline Fulton's $K^{\mathrm{a}}$ & $1.01 \pm 0.10(0.67-1.22)$ & $0.93 \pm 0.13(0.61-1.10)$ & $0.98 \pm 0.12(0.61-1.22)$ \\
\hline Presence of internal helminths & $32(52 \%)$ & $16(53 \%)$ & $48(53 \%)$ \\
\hline Coelomic helminths ${ }^{\mathrm{b}}$ & $32(52 \%)$ & $13(43 \%)$ & $45(49 \%)$ \\
\hline Intestinal cestodes & $2(3 \%)$ & $4(13 \%)$ & $6(7 \%)$ \\
\hline Presence of copepods & $14(23 \%)$ & $6(20 \%)$ & $20(22 \%)$ \\
\hline
\end{tabular}

cles to detect areas of discoloration or texture variation, was done on each fish. To measure the microsporidia spore, wet mount preparations were made from frozen muscular tissue of 1 specimen with gross lesions. The presence of external parasites (gill copepods morphologically characteristic of Salmincola sp.) and internal parasites (Anisakidae larvae, adult Philonema sp., plerocercoids of cestodes morphologically suggestive of Diphyllobothrium sp. and adult intestinal cestodes) was noted for each fish as a binary variable, i.e. 'presence' or 'absence' (Table 1).

\subsection{Histologic evaluation}

A systematic sampling of muscles, composed of 4 muscle sections of $1 \mathrm{~cm} \times 1 \mathrm{~cm} \times 0.5 \mathrm{~cm}$ thick sampled along the midline of each fillet, was conducted on each fish for histological examination (total of 8 muscle sections per fish). The muscle sections collected were fixed in ExCell Plus ${ }^{\circledR}$, embedded in paraffin, cut with a microtome in $3 \mu \mathrm{m}$ sections and stained with hematoxylin phloxine saffron for light microscopy. The presence of microsporidia was assessed for each specimen. A diagnosis of microsporidiosis was given when microsporidia were detected in at least one of the examined muscle sections, regardless of the presence of associated inflammation. For each fish infected by microsporidia, the severity of the infection was defined as the mean percentage of the examined muscle area affected by the parasite (mean of the 8 muscle sections). To do this, the con- trast between affected and non-affected areas was enhanced using Adobe Photoshop on numerized images of each histological slide (Aperio ImageScope software, version 12.4.0, Leica Biosystems Imaging). The percentage of affected areas was then determined using the color threshold tool in ImageJ software (Schneider et al. 2012). For each image, the threshold set in Image J was set at the discretion of the operator to optimally cover the affected areas without covering the non-affected muscle. Histologic evaluation (detection of microsporidia and determination of the severity of the infection) was performed by the same investigator (M.J.).

\subsection{Microsporidia characterization}

Muscle tissue from macroscopic lesions of 2 specimens was preserved in $4 \%$ formaldehyde and $1 \%$ glutaraldehyde in $0.1 \mathrm{M}$ phosphate buffer (PB) (pH 7.4) and processed for transmission electron microscopy (TEM). Tissues were post-fixed in $1 \%$ $(\mathrm{w} / \mathrm{v})$ osmium tetroxide in $0.2 \mathrm{M}$ sodium cacodylate buffer for $1 \mathrm{~h}$ prior to embedding in epoxy resin. Thick sections were cut $(0.5 \mu \mathrm{m})$ and stained with toluidine blue. Ultrathin sections $(30-40 \mu \mathrm{m})$ were cut and stained for $1.5 \mathrm{~h}$ in $5 \%(\mathrm{w} / \mathrm{v})$ aqueous uranyl acetate solution followed by lead citrate. TEM was performed using an FEI Titan 80-200 TEM/STEM, and images were captured using an UltraScan 1000XP model 994 camera at the Oregon State University Electron Microscopy Center. 
DNA was extracted from frozen muscle tissues stored in $95 \%$ ethanol from 7 infected fish (4 females, 3 males; diagnosed by histology) using the Qiagen Blood and Tissue Extraction kit following the manufacturer's protocol. PCR was performed using the general microsporidian ribosomal gene primers $18 \mathrm{~F}$ (5'-CAC CAG GTT GAT TCT GCC-3') and 580R (5'-GGT CCG TGT TTC AAG ACG G-3') to amplify the $5^{\prime}$ region of the small subunit ribosomal DNA (SSU rDNA) gene. All reactions were performed in $50 \mu \mathrm{l}$ volumes using the Platinum PCR Supermix (Invitrogen), $0.9 \mathrm{mmol}$ each forward and reverse primer and $5 \mu \mathrm{l}$ of DNA template. Amplifications were performed on a VeritiPro thermal cycler (ThermoFisher), with the following protocol: initial denaturation at $94^{\circ} \mathrm{C}$ followed by 35 cycles of $94^{\circ} \mathrm{C}$ for $30 \mathrm{~s}$, annealing at $55^{\circ} \mathrm{C}$ for $30 \mathrm{~s}$ and extension at $72^{\circ} \mathrm{C}$ for $1 \mathrm{~min}$. The resulting PCR products were purified using the QIAquick PCR Purification Kit (Qiagen), and Sanger sequencing was performed using the primers used for PCR with the addition of 530F (5'-GTG CCA GCM GCC GCG-3') and 1061F (5'-GGT GGT GCA TGG CCG-3'). The overlapping sequence reads were manually assembled using BioEdit, and the resulting consensus sequence was searched against the National Center for Biotechnology Information non-redundant nucleotide database using the BLASTn interface. Sequences with high similarity were selected and aligned using MUSCLE (Edgar 2004). Phylogenetic reconstruction was performed using MrBayes v.3.2.6 (Huelsenbeck et al. 2001) as implemented in Geneious Prime (v.2021.0.3) with a general time-reversible substitution model with inverse gamma rate variation, a chain length of 1100000 and a 100000 burn-in. Nucleospora salmonis (GenBank accession number NSU78176) was selected as the outgroup taxon.

\subsection{Statistical analysis}

The statistical analysis was performed using SAS software, version 9.4 (SAS Institute) and R version 4.0.0 (R Core Team 2020). Univariate logistic regressions were used to evaluate the association between the presence of microsporidia and each of the following independent variables: age (yr), sex, Fulton's condition factor $(K)$, lake of capture, fork length $(\mathrm{cm})$ and weight $(g)$ of the fish, presence of internal parasites and presence of external parasites. The infection severity data were normalized using log base 10 transformation. Pearson's correlation coefficient was used in order to evaluate the associations between the logtransformed infection severity data and each quanti- tative variable, i.e. age, weight, fork length and $K$. Univariate linear models were used to explore associations between log-transformed infection severity and each qualitative variable, i.e. sex, lake of capture, presence of internal parasites and presence of external parasites, taking into account unequal variances where needed. Independent variables with $\mathrm{p}$-values < 0.15 in the above univariate linear models or Pearson's correlation coefficient analyses were retained in a multiple linear model with log-transformed infection severity as the dependent variable. The level of statistical significance was set at $5 \%$.

\section{RESULTS}

\subsection{Microsporidian infection}

Out of 91 fish examined, 4 (4.3\%) presented muscle anomalies detectable during the macroscopic examination. These muscular changes were characterized by focal or multifocal discoloration and fibrous aspect of the flesh (Fig. 1). Wet mount preparation exhibited a large quantity of spores (>100 spores per field at 400× magnification). Spores were oval with a posterior vacuole and measured (mean \pm SD) $2.28 \pm$ $0.08 \mu \mathrm{m} \times 1.02 \pm 0.09 \mu \mathrm{m}$. Occasionally, spores were inside sporophorous vesicles, containing more than 20 spores (Fig. 2A). On histological examination, the microsporidia detected in fish muscle appeared mostly as free spores or less frequently as sporophorous vesicles in the muscle in 93 and $41 \%$ of the affected fish, respectively (Fig. 2B,C). The sporophorous vesicles were round to irregular in shape and were composed of a thin eosinophilic membrane surrounding numerous developmental stages. The vesicles were located within the sarcoplasm, repelling myofibrils on both sides, but rarely distended the myocytes. These

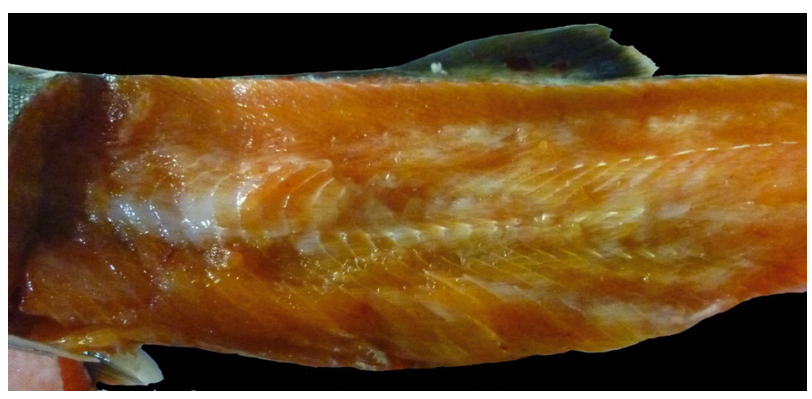

Fig. 1. Severe muscular damage caused by microsporidian infection in an Arctic char Salvelinus alpinus from Nunavik, Canada. Note the multifocal discoloration and the fibrous appearance of the affected flesh 

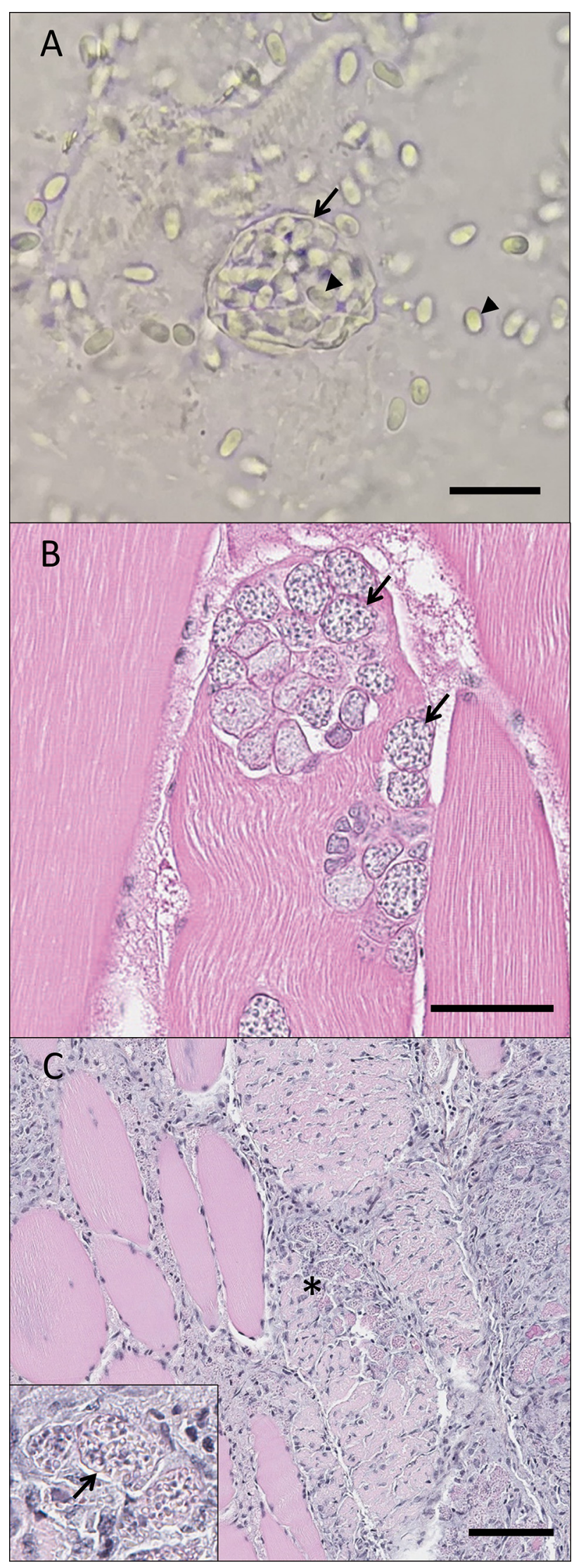

sporophorous vesicles were usually not associated with an inflammatory response or histological evidence of destruction of the fibers. In contrast, free mature spores were present in fragmented muscular fiber and in adjacent connective tissues. These free spores were associated with destruction of myocytes and mild to extensive infiltration by macrophages (Fig. 2B,C).

Microsporidian infections were diagnosed by microscopy in 56 out of 91 collected fish (61\%). Results of univariate logistic regression with odds ratio (OR), $95 \%$ confidence interval (CI) and p-value of each independent variable are summarized in Table 2 . We detected no statistical difference in the presence of microsporidia between the 2 lakes, with $66 \%$ (40/61) and $53 \%(16 / 30)$ of the sampled fish affected in Lake Duquet and Lake Françoys-Malherbe, respectively $(p=0.26)$. A positive association was observed between the presence of microsporidia and age, length and weight of the fish. No association was detected between the presence of microsporidia and sex, Fulton's condition factor $(K)$ or the presence of internal or external parasites ( $\mathrm{p}>0.05)$.

The severity of the infection (mean percentage of the muscle area affected by the infection) ranged from 0.01 to $48.6 \%$ of the total surface of muscle examined. It was very low $(<1 \%)$ in $75 \%(42 / 56)$ of the infected cases (Figs. $3 \& 4$ ). For $21.4 \%$ of the infected individuals (12/56), lesions represented 1 to $7 \%$ of the total surface of muscle examined. Two individuals $(3.6 \%)$ presented lesions involving large portions of the area examined (37.2 and 48.6\%). Multifocal discolorations of the flesh were visible macroscopically in both specimens (Fig. 1). Based on univariate linear models, the severity of the infection was significantly higher in females than in males $(p=0.001)$ and in fish infected by internal parasites $(p=0.023)$. The sever-

Fig. 2. Microscopic characteristics of microsporidia infecting the muscle of Arctic char Salvelinus alpinus from Nunavik, Canada. (A) Wet mount preparation made from frozen muscular tissue of 1 specimen with gross lesions. Several free spores (arrowheads) and 1 sporophorous vesicle (arrow) containing spores (arrowheads) are visible. Scale bar $=5 \mu \mathrm{m}$. (B) Histological section of microsporidia-infected muscle showing intracytoplasmic sporophorous vesicles (arrows) containing spores in formation. Scale bar $=50 \mu \mathrm{m}$. (C) Histological section of microsporidia-infected muscle showing mature spores in tissue. The free spores are associated with severe destruction of muscular fibers and massive histiocytic infiltration within the muscular fiber and in connective tissue. Asterisk: fragmented and infiltrated muscle fiber with sporophorous vesicles releasing mature spores. Scale bar = $100 \mu \mathrm{m}$. Inset: higher magnification of these sporophorous vesicles (arrow) and mature spores 
Table 2. Assessment of the association between the presence of microsporidian infection in Arctic char Salvelinus alpinus (Nunavik, Canada) and several variables, i.e. age, sex, Fulton's condition factor $(K)$, lake of capture, fork length and total weight of the fish, and presence of internal and external parasites, using univariate logistic regressions. Odds ratios (ORs; 'Reference': reference parameter for the analysis, with OR $=1$ ), $95 \%$ confidence intervals (CIs) and p-values are given for each independent variable

\begin{tabular}{|lcc|}
\hline Factor & OR $(95 \%$ CI) & $\mathrm{p}$ \\
\hline Age (yr) & $1.513(1.129-2.028)$ & 0.0056 \\
Fork length (cm) & $1.092(1.035-1.166)$ & 0.0031 \\
Total weight (g) & $1.001(1.000-1.002)$ & 0.0080 \\
Fulton's $K$ & $25.8(0.62-1423.53)$ & 0.0946 \\
Lake & Reference & \\
$\quad$ Françoys-Malherbe & $1.667(0.684-4.062)$ & 0.2610 \\
$\quad$ Duquet & Reference & \\
Sex & $1.064(0.443-2.557)$ & 0.8901 \\
$\quad$ Male & Reference & \\
$\quad$ Female & $0.904(0.385-2.110)$ & 0.8163 \\
Internal parasites & Reference & \\
$\quad$ Absence & Presence & \\
External parasites & Absence & \\
$\quad$ Presence & & \\
\hline
\end{tabular}

ity of the infection was also negatively correlated with Fulton's $K(\mathrm{r}=-0.32 ; \mathrm{p}=0.014)$. There was no significant association between the severity of the infection and the other variables $(p>0.05)$. In the multivariable linear model including sex, condition factor, presence of internal parasites and presence of external parasites, Fulton's $K$ remained negatively

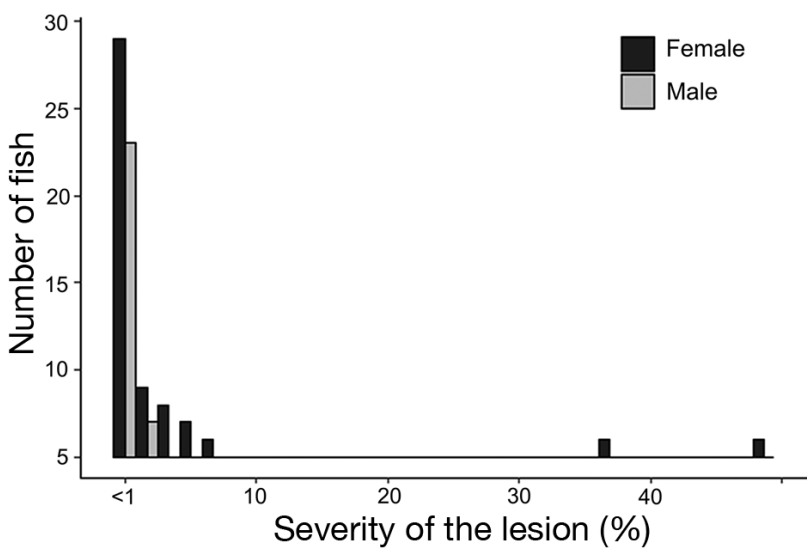

Fig. 4. Severity of the microsporidian infection affecting Arctic char Salvelinus alpinus females $(\mathrm{n}=36)$ and males ( $n=20$ ) from Nunavik, Canada. Severity of infection is defined as the average percentage of muscle area affected by microsporidia

correlated with the severity of the lesion $(p=0.028)$, and the effect of the sex remained significant as above $(p=0.046)$. Back-transformed means of the severity of infection with 95\% confidence intervals were $0.217 \%$ (95\% CI: $0.091-0.517 \%$ ) and $0.040 \%$ (95\% CI: $0.019-0.086 \%$ ) for females and males, respectively.

\subsection{Electron microscopy}

Transmission electron microscopy (TEM) of the muscle lesions showed dense mature spores (Fig. 5) either free in the matrix of the lesion (Fig. 5A) or enclosed
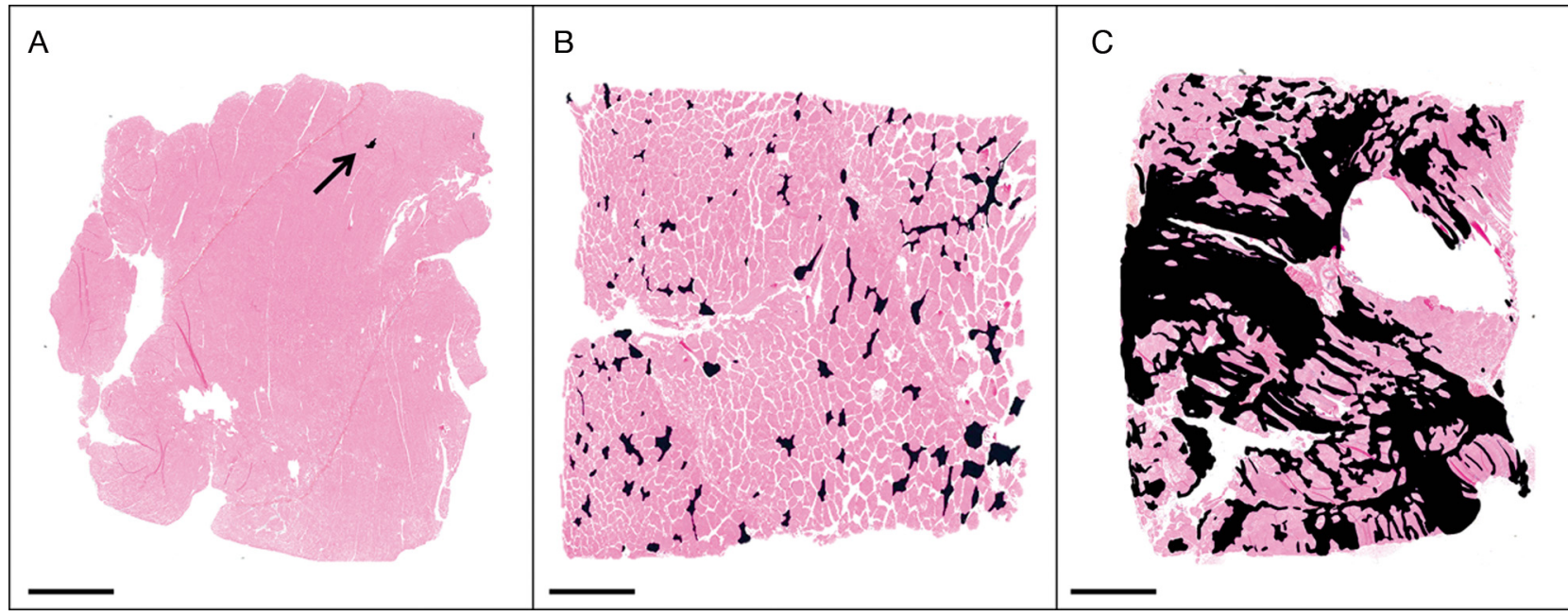

Fig. 3. Muscular sections of Arctic char Salvelinus alpinus from Nunavik, Canada, showing different severities of microsporidian infections. The affected areas (black) were enhanced using Photoshop. (A) Minimal and focal lesion ( $<1 \%$ of the surface area) (arrow), (B) mild and multifocal lesions (1-10\% of the surface area) and (C) marked and multifocal to coalescent lesions ( $>30 \%$ of the surface area). Scale bars $=2 \mathrm{~mm}$ 


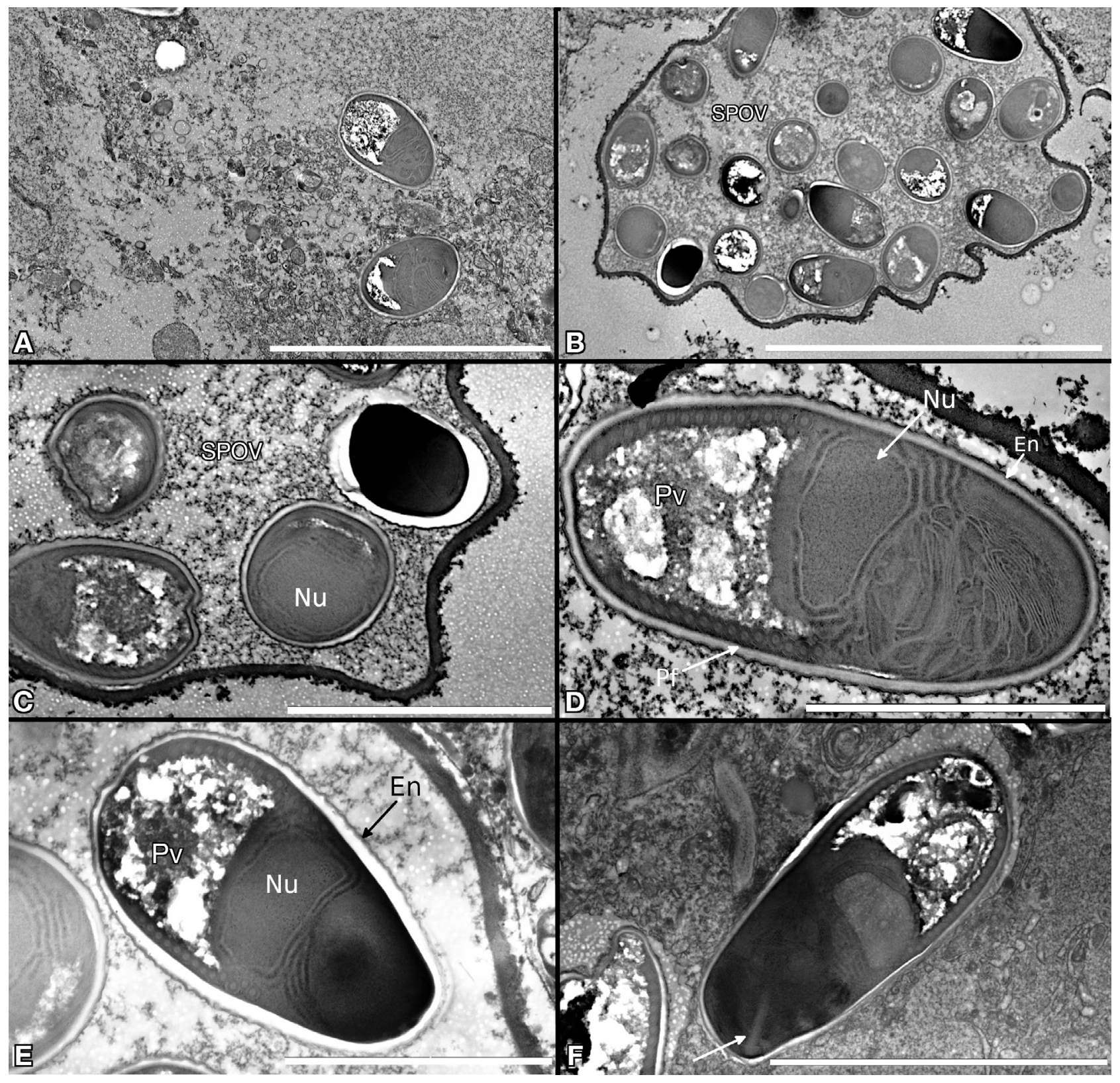

Fig. 5. Transmission electron microscopy of mature spores of Microsporidium sp. from skeletal muscle of Arctic char Salvelinus alpinus. (A) Free mature spores of Microsporidium sp. surrounded by myonecrotic material. Scale bar = $20 \mu \mathrm{m}$. (B) Sporophorous vesicle (SPOV) containing numerous mature spores. Scale bar $=20 \mu \mathrm{m}$. (C) Single nucleus (Nu) visible in a transverse section of mature spore near the margin of a sporophorous vesicle (SPOV). Scale bar $=5 \mu$ m. (D) Longitudinal section of a mature spore with a thick endospore wall (En), single nucleus (Nu) and characteristic posterior vacuole (Pv). Transverse sections of the isofilar polar filament structure (Pf) are visible. Scale bar $=3 \mu \mathrm{m}$. (E) Longitudinal section of mature spore with thick endospore wall (En), single nucleus $(\mathrm{Nu})$ and posterior vacuole $(\mathrm{Pv})$ at increased magnification. Scale bar $=3 \mu \mathrm{m}$.

(F) Manubroid portion of the polar filament (arrow) visible in a mature spore. Scale bar $=5 \mu \mathrm{m}$

within a sporophorous vesicle containing numerous spores (Fig. 5B). Spores were characterized by the appearance of a thick endospore wall surrounded by an exospore (Fig. 5A,E) and contained a prominent posterior vacuole (Fig. 5D,E), a single nucleus (Fig. 5B-E) and 16-17 turns of the polar tubule that appeared to be uniform in diameter (i.e. isofilar) (Fig. 5D-F). The lamellar polaroplast was visible in cross section tightly packed in the anterior portion of the spore adjacent to the tubular polaroplast, beginning approximately at the midpoint. The polaroplast comprised well-defined lamellar membranes, which occupied 


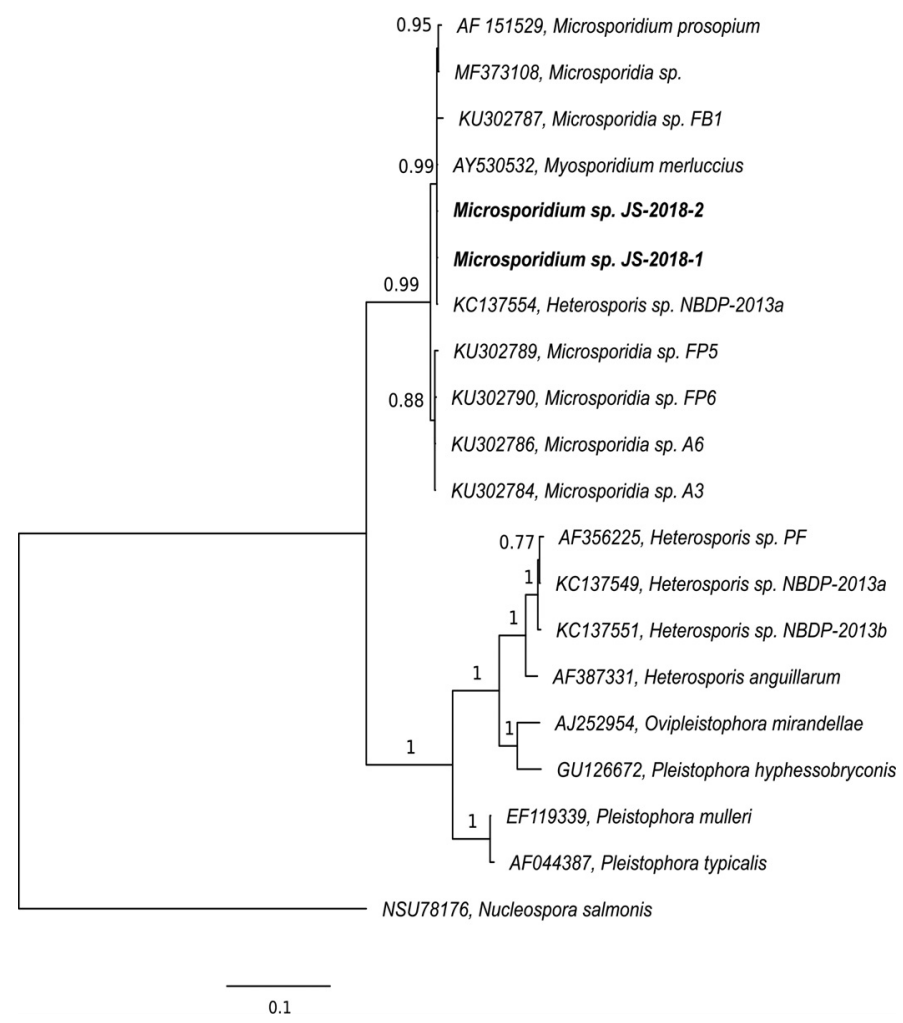

Fig. 6. Phylogenetic tree of small subunit ribosomal RNA gene sequences of microsporidian species infecting fish as inferred by Bayesian analysis. Bold font highlights 2 Microsporidium sp. isolates from Arctic char skeletal muscle lesions. Numbers at nodes represent Bayesian posterior probability support. GenBank accession numbers are also shown

about $40 \%$ of the spore. The endospore was distinct, about $0.061 \mu \mathrm{m}$, whereas the electron dense exospore is thin, about $0.0068 \mu \mathrm{m}$. No presporogonic developmental stages were observed.

\subsection{Molecular analysis}

Identical partial sequences (1564 bp) of the SSU rDNA gene were obtained from 2 individuals. The partial sequences were identical to those of an isolate identified as Heterosporis sp. (GenBank accession number KC137554) and closely related to several sequences identified as belonging to Microsporidium and Myosporidium. Phylogenetic analysis performed on an alignment of an approximately $1300 \mathrm{bp}$ region with several fish-infecting microsporidian sequences obtained from GenBank placed the sequences within the clade of members of the collective group genus Microsporidium (Fig. 6). Both sequences are available from GenBank under accession numbers MW429835 and MW429836.

\section{DISCUSSION}

Microsporidian infections are relatively common in fish. Several species of microsporidia have already been reported to infect muscle of salmonids (Lom 2002, Kent et al. 2014), but to our knowledge, muscular microsporidiosis has not been described in Arctic char.

We provisionally assigned the microsporidium described here to the genus Microsporidium. The generic name Microsporidium is a collective group name used for 'identifiable species of which generic positions for the time being are uncertain' (Sprague 1977, p. 26). Several members of this clade have been placed in the genus Myosporidium, such as M. spraguei (Jones et al. 2017) and M. merluccius (Baquero et al. 2005), and all are myotropic microsporidian parasites of fishes. The SSU rDNA gene obtained in the present study was identical to that of an organism identified as a Heterosporis sp. (KC137554) isolated from a cisco (Coregonus sp.) in the Great Lakes (Phelps et al. 2015). However, there is little sequence variation in region of the SSU rDNA genes that are available for members of this clade, suggesting that further sequencing, perhaps of a different gene, is needed to resolve the taxonomy of this group.

While microsporidian infections are well studied in farmed fish (Figueras et al. 1992, Kent et al. 2014, Ahonen 2017) and in captive reared fish (Chow et al. 2016), there are few detailed studies on the prevalence of this organism in wild fish populations. The present study shows an apparent prevalence of microsporidian infection of $61 \%$ in a wild population of Arctic char in Nunavik. Because the sensitivity of the detection by the method used (histology) is unknown, but is obviously not $100 \%$, the prevalence documented in this study is likely an underestimation of the real prevalence in this population. The similarity between samples from the 2 lakes in terms of the observed prevalence and severity of microsporidia infections is not unexpected, because these 2 lakes are part of the same hydrographic system and hold similar biological communities. The apparent prevalence observed in this population is similar to prevalences reported for microsporidia in other populations of wild fish, in which prevalence could reach up to $80 \%$ (Miller 2009, Ryan \& Kohler 2016, Ahonen 2017, Tomamichel et al. 2018). In the present study, only a small proportion of specimens examined showed severe infections ( $3.6 \%$ ), which is similar to that reported for freshwater sculpins Cottus spp. $(<5 \%)$ (Ryan \& Kohler 2016), but lower than in pikeperch Sander lucioperca (10\%), burbot Lota lota 
(14\%) (Ahonen 2017) and yellow perch Perca flavescens $(25 \%)$ (Tomamichel et al. 2018). Thus, the level of infection by microsporidia in this population of fish from the Salluit region does not seem unusual compared to other populations of wild fish. Nevertheless, it is unknown if the microsporidian species found in these char populations is an emerging pathogen or a native pathogen to the region previously undetected.

The infection by microsporidia was associated with macroscopic changes in only $7.1 \%(4 / 56)$ of the fish for which the infection was confirmed by histology. This shows that the gross examination of the fillets has a very low sensitivity of detection for this condition. Nevertheless, the presence of areas of discoloration and fibrosis is suggestive of extensive infection by this organism in this population of char.

Older (larger) fish were more often infected than younger (smaller) ones, which might be explained by an increase of the opportunities of exposure to the organism either through the water column or via predation of infected prey consumed out at sea, as anadromous Arctic char are fasting at Deception Bay (Martyniuk et al. 2020). The positive association between the presence and the size of the fish may support exposure via predation since the size of fish is directly correlated to total food intake. This increase in occurrence with age could also be caused by differences in food preferences between young (small) and older fish. Because cannibalism is known to occur in this species (Amundsen 1994), larger and older fish may be more exposed to microsporidiosis by cumulative predation of infected younger fish. The absence of correlation between age and the severity of infection suggests that infections are not cumulative, implying remissions between successive infections. Recovery and development of immunity to microsporidian infection have been reported in some salmonids (Kent \& Speare 2005). This association between age and presence, but not with severity of infection, contrasts with infections of yellow perch by the microsporidium Heterosporis sutherlandae in Minnesota (USA), where the severity of infections increases with age (Tomamichel et al. 2018). The authors of that report suggested that either the infection is cumulative (implying no remission) or that by consuming fish already infected with $H$. sutherlandae, older fish receive a higher dose of the organism, causing a more severe infection (Tomamichel et al. 2018).

The reason why female Arctic char are more severely affected than males remains unclear. Gender predisposition in microsporidian infection varies greatly among studies, with no clear explanation (Chow et al. 2016, Ryan \& Kohler 2016, Ahonen 2017, Tomamichel et al. 2018). Differences in response to stress may be a plausible explanation, for example hierarchy structures between males and females as proposed by Chow et al. (2016) to explain a male sex bias in zebrafish Danio rerio in the prevalence of Pseudoloma neurophilia.

Infections by several microsporidian species are known to increase mortality or decrease body condition of the host. Muscular infections by microsporidia have been associated with reduced growth, muscle destruction and impaired swimming capacity, which may increase indirect mortality due to failure to capture prey or escape predation (Sprengel \& Lüchtenberg 1991, Figueras et al. 1992, Miller 2009, Kent et al. 2014, Phelps et al. 2015). However, microsporidian infections in pike-perch and burbot were not associated with a decrease in body condition (Ahonen 2017), whereas the severity of these infections in yellow perch increased with body condition (Tomamichel et al. 2018). In the present study, most of the fish were in good body condition, with a Fulton's condition factor $(K)$ of $0.98 \pm 0.12$ (mean $\pm \mathrm{SD}$ ), similar to that reported for both lakes during the post-winter 2017 sampling season $(K=0.91 \pm 0.11)$ (Martyniuk et al. 2020). In addition, $K$ was not correlated with the presence of the microsporidia. However, among the infected Arctic char, the multivariable linear regression showed a negative correlation between the severity of infection and $K$. This negative relationship suggests that muscular changes associated with microsporidian infection could decrease the capacity of heavily affected fish in capturing prey. The infection may also be associated with additional energy expenditures to mount inflammatory and repair processes. No association was found between internal (nematodes, cestodes) or external (copepods) parasitism and the presence or severity of microsporidian infection in the present study, whereas some microsporidian infections have been associated with host immunosuppression in previous studies (Figueras et al. 1992, Kent et al. 2014).

Although the impact of infection by microsporidia at the population level remains unclear, the high prevalence associated with a low rate of high-severity infection suggests that microsporidia have little impact on the Arctic char populations in Lake Duquet and Lake Françoys-Malherbe. Alternatively, a higher mortality rate in fish with a high level of infection, following either starvation or increased risk of predation, could also result in a similar pattern of the infection severity in this population. 
One of the reasons why this project was conducted was to investigate potential links between this organism and the occurrence of upper digestive tract symptoms reported in humans following the consumption of raw meat from Arctic char caught in these lakes. Although some species of microsporidia, such as Encephalitozoon cuniculi (McInnes \& Stewart 1991) and Enterocytozoon bieneusi (Cama et al. 2007), are known to be zoonotic, there is currently no clear evidence for the transmission of microsporidia between fish and humans. Because species of Pleistophora spp. are found in the muscle of many species of fish (Lom 2002), some authors have suggested a possible fish-human transmission route for cases of skeletal muscle infections by Pleistophora ronneafiei (Cali et al. 2005) and the closely related Trachipleistophora hominis (Cheney et al. 2000, Curry et al. 2005) in people. However, since human infection by ingestion of poorly cooked infected meat from fish has not been confirmed to date, this potential link remains speculative (Fayer \& Santin-Duran 2014).

In addition, most of the known human-pathogenic species of microsporidia infect the lower gastrointestinal tract (intestines) and cause chronic diarrhea and wasting syndrome (Weiss 2014), but not acute vomiting and tingling sensations in the mouth as reported in Salluimiut following the consumption of Arctic char. Moreover, clinical manifestations of microsporidian infections in people remain rare and usually affect immunocompromised individuals (Fayer \& Santin-Duran 2014, Weiss 2014). Consequently, it is unlikely that the symptoms reported by Inuit fishermen are caused by the ingestion of microsporidia. Nevertheless, we still recommend avoiding the consumption of flesh presenting areas of discoloration or abnormal texture as shown in Fig. 1. Even if freezing the meat might potentially inactivate the microsporidia, thermotolerance varies greatly among species of microsporidia. Several species of fish microsporidia seem to be inactivated by freezing at $-20^{\circ} \mathrm{C}$ for 24 to $48 \mathrm{~h}$ (Li \& Fayer 2006, Miller 2009, Leiro et al. 2012), but others, such as spores of Glugea stephani from flatfish, held at $-19^{\circ} \mathrm{C}$ for $24 \mathrm{~h}$ were considered viable based on a filament extrusion test (Amigó et al. 1996), and P. neurophilia spores can survive cryopreservation (even if survival is reduced) (Norris et al. 2018). As spores may be more resistant to low temperatures, given that the host fish lives in northern cold waters, further studies are needed to determine if microsporidia spores isolated from these Arctic char are inactivated by freezing.

In addition to the microsporidia, the examination of the fish revealed the presence of nematode larvae of the family Anisakidae at the surface of the organs. Anisakid parasites are widely distributed in the marine environment, infecting invertebrates, fish, birds and marine mammals. Humans are considered a dead end or accidental host for this parasite. However, cases of anisakiasis associated with consumption of undercooked meat (raw, smoked, salted) from fish infected with Anisakidae are reported on a regular basis (Jenkins et al. 2013, Bao et al. 2019, Centers for Disease Control and Prevention 2019). Anisakidae larvae can penetrate the gastro-intestinal mucosa and cause tingling in the esophagus, nausea, vomiting, abdominal pain, diarrhea and/or fatigue (Jenkins et al. 2013). However, cases associated with Arctic char are quite rare. One case of anisakiasis has been reported in an Inuk woman who had eaten raw Arctic char in Nunavik (Bhat \& Cleland 2010). The potential link between anisakid larvae in fish and the symptoms observed in Inuit warrants further investigations. Arctic char are also parasitized by plerocercoids of cestodes, most likely Diphyllobothrium sp. Likewise, some species of diphyllobothriid cestodes (e.g. D. latum and D. dendriticum) are zoonotic, and contamination in people occurs by consumption of undercooked meat. Most human infections are asymptomatic, but symptoms can include abdominal discomfort, diarrhea, vomiting and weight loss (Jenkins et al. 2013, Centers for Disease Control and Prevention 2012). Anisakid larvae and plerocercoid cestodes are both destroyed by freezing at $-20^{\circ} \mathrm{C}$ for at least $7 \mathrm{~d}$ (US Food and Drug Administration 2017). Manual removal of larvae is also recommended but is not sufficient, since these larvae are not always easy to detect in the flesh. Other causes of food poisoning (bacteria, virus contamination) cannot be ruled out in our study, and may also explain the digestive signs reported in Salluimiut.

\section{CONCLUSION}

This study documented a high prevalence of microsporidiosis in Arctic char from 2 lakes in Nunavik, Canada. The severity of infection was low in most cases and similar to what has been reported in other populations of wild fish. Although the impact of infection by microsporidia at the population level remains unclear, the pattern of this infection suggests that microsporidia have little impact on these Arctic char populations. At the individual level, however, the negative correlation observed between the severity of infection and body condition suggests a potential impact of this organism on fish health. Even if the 
link between microsporidia and the symptoms described by Inuit fishermen remains unlikely, we still recommend to avoid eating meat presenting macroscopic anomalies. Nevertheless, since the importance of Arctic char in the traditional Inuit subsistence diet is fully recognized, the consumption of this food source should be encouraged. The link between the symptoms reported by Inuit fisherman and other potential causes, such as the presence of Anisakidae larvae, warrants further investigation. Freezing of the fish at $-20^{\circ} \mathrm{C}$ for at least $1 \mathrm{wk}$ might decrease the risk of transmission of helminth parasites and microsporidia. Finally, this study provides baseline data that could be used in the future to access the impact of environmental changes on the relationship between this parasite and its host.

Acknowledgements. We thank Sandy Suppa (Wildlife Technician, Makivik Corporation, Nunavik), Francis Demers (Wildlife Technician, MFFP-Chibougamau), the many Inuit fishermen and the employees of Raglan Mine for their support with this project. We also thank Guy Beauchamp for his assistance with the statistics, and Peter May (Wildlife Technician, Makivik Corporation, Nunavik) for ageing all Arctic char analyzed in this study.

\section{LITERATURE CITED}

Ahonen H (2017) Spore-forming parasites infecting muscles of freshwater fishes: ecology and epidemiology. $\mathrm{PhD}$ dissertation, University of Jyväskylä

*Amigó JM, Gracia MP, Rius M, Salvadó H, Maillo PA, Vivarés CP (1996) Longevity and effects of temperature on the viability and polar-tube extrusion of spores of Glugea stephani, a microsporidian parasite of commercial flatfish. Parasitol Res 82:211-214

Amundsen PA (1994) Piscivory and cannibalism in Arctic charr. J Fish Biol 45:181-189

Bao M, Pierce GJ, Strachan NJ, Pascual S, González-Muñoz M, Levsen A (2019) Human health, legislative and socioeconomic issues caused by the fish-borne zoonotic parasite Anisakis: challenges in risk assessment. Trends Food Sci Technol 86:298-310

Baquero E, Rubio M, Moura INS, Pieniazek NJ, Jordana R (2005) Myosporidium merluccius n. g., n. sp. infecting muscle of commercial hake (Merluccius sp.) from fisheries near Namibia. J Eukaryot Microbiol 52:476-483

Bhat M, Cleland P (2010) Gastric anisakiasis. Clin Gastroenterol Hepatol 8:A20

Cali A, Weiss LM, Takvorian PM (2005) A review of the development of two types of human skeletal muscle infections from microsporidia associated with pathology in invertebrates and cold-blooded vertebrates. Folia Parasitol 52:51-61

Cama VA, Pearson J, Cabrea L, Pacheco L and others (2007) Transmission of Enterocytozoon bieneusi between a child and guinea pigs. J Clin Microbiol 45:2708-2710

Campana SE, Thorrold SR (2001) Otoliths, increments, and elements: keys to a comprehensive understanding of fish populations? Can J Fish Aquat Sci 58:30-38
Centers for Disease Control and Prevention (2012) Parasites Diphyllobothrium infection. www.cdc.gov/parasites/ diphyllobothrium/index.html (accessed 15 May 2020)

* Centers for Disease Control and Prevention (2019) Parasites anisakiasis. www.cdc.gov/parasites/anisakiasis/ (accessed 15 May 2020)

* Cheney SA, Lafranchi-Tristem NJ, Canning EU (2000) Phylogenetic relationships of Pleistophora-like microsporidia based on small subunit ribosomal DNA sequences and implications for the source of Trachipleistophora hominis infections. J Eukaryot Microbiol 47:280-287

* Chow FW, Xue L, Kent ML (2016) Retrospective study of the prevalence of Pseudoloma neurophilia shows male sex bias in zebrafish Danio rerio (Hamilton-Buchanan). J Fish Dis 39:367-370

* Curry A, Beeching NJ, Gilbert JD, Scott G, Rowland PL, Currie BJ (2005) Trachipleistophora hominis infection in the myocardium and skeletal muscle of a patient with AIDS. J Infect 51:e139-e144

*Edgar RC (2004) MUSCLE: multiple sequence alignment with high accuracy and high throughput. Nucleic Acids Res 32:1792-1797

Fayer R, Santin-Duran M (2014) Epidemiology of Microsporidia in human infections. In: Weiss LM, Becnel JJ (eds) Microsporidia: pathogens of opportunity. Wiley Blackwell, Ames, IA, p 135-164

*Figueras A, Novoa B, Santarém M, Martínez E, Alvarez JM, Toranzo AE, Dyková I (1992) Tetramicra brevifilum, a potential threat to farmed turbot Scophthalmus maximus. Dis Aquat Org 14:127-135

Fisheries and Oceans Canada (2014) Arctic char. www.dfompo.gc.ca/fisheries-peches/sustainable-durable/fish eries-peches/char-omble-eng.html (accessed 15 May 2020)

*Huelsenbeck JP, Ronquist F, Nielsen R, Bollback JP (2001) Bayesian inference of phylogeny and its impact on evolutionary biology. Science 294:2310-2314

Jenkins EJ, Castrodale LJ, de Rosemond SJC, Dixon BR and others (2013) Tradition and transition: parasitic zoonoses of people and animals in Alaska, Northern Canada, and Greenland. Adv Parasitol 82:33-204

Jones SRM, Ahonen HS, Granlund L, Arsiola T, Taskinen J (2017) Two novel microsporidia in skeletal muscle of pike-perch Sander lucioperca and burbot Lota lota in Finland. J Parasitol 103:95-102

Kent ML, Speare DJ (2005) Review of the sequential development of Loma salmonae (Microsporidia) based on experimental infections of rainbow trout (Oncorhynchus mykiss) and Chinook salmon (O. tshawytscha). Folia Parasitol 52:63-68

Kent ML, Docker M, Khattra J, Vossbrinck CR, Speare DJ, Devlin RH (1999) A new Microsporidium sp. (Microsporidia) from the musculature of the mountain whitefish Prosopium williamsoni from British Columbia: morphology and phylogeny. J Parasitol 85:1114-1119

Kent ML, Shaw RW, Sanders JL (2014) Microsporidia in fish. In: Weiss LM, Becnel JJ (eds) Microsporidia: pathogens of opportunity. Wiley Blackwell, Ames, IA, p 493-520

Kuhnlein HV, Humphries MM (2017) Traditional animal foods of indigenous peoples of northern North America. Arctic char. http://traditionalanimalfoods.org/fish/searunfish/page.aspx?id=6449 (accessed 15 May 2020)

* Leiro JM, Piazzon C, Domínguez B, Mallo N, Lamas J (2012) Evaluation of some physical and chemical treatments for inactivating microsporidian spores isolated from fish. Int 
J Food Microbiol 156:152-160

Li X, Fayer R (2006) Infectivity of microsporidian spores exposed to temperature extremes and chemical disinfectants. J Eukaryot Microbiol 53:S77-S79

Lom J (2002) A catalogue of described genera and species of microsporidians parasitic in fish. Syst Parasitol 53: 81-99

Martyniuk MAC, Couture P, Tran L, Beaupré L, Power M (2020) Seasonal variation of total mercury and condition indices of Arctic charr (Salvelinus alpinus) in Northern Québec, Canada. Sci Total Environ 738:139450

McInnes EF, Stewart CG (1991) The pathology of subclinical infection of Encephalitozoon cuniculi in canine dams producing pups with overt encephalitozoonosis. J S Afr Vet Assoc 62:51-54

Miller PE (2009) Diagnosis, prevalence, and prevention of the spread of the parasite Heterosporis sp. (Microsporidia: Pleistophoridae) in yellow perch (Perca flavescens) and other freshwater fish in Northern Minnesota, Wisconsin, and in Lake Ontario. MSc thesis, University of Wisconsin, La Crosse, WI

Norris LJ, Watral V, Kent ML (2018) Survival of bacterial and parasitic pathogens from zebrafish (Danio rerio) after cryopreservation and thawing. Zebrafish 15:188-201

Phelps NBD, Mor SK, Armién AG, Pelican KM, Goyal SM (2015) Description of the microsporidian parasite, Heterosporis sutherlandae n. sp., infecting fish in the Great Lakes Region, USA. PLOS ONE 10:e0132027

R Core Team (2020) R: a language and environment for statistical computing. 4.0.0. R Foundation for Statistical Computing, Vienna

Ricker WE (1975) Computation and interpretation of biological statistics of fish populations. Bull Fish Res Board Can

Editorial responsibility: Dieter Steinhagen, Hannover, Germany

Reviewed by: 3 anonymous referees
191:1-382

* Ryan JA, Kohler SL (2016) Distribution, prevalence, and pathology of a microsporidian infecting freshwater sculpins. Dis Aquat Org 118:195-206

Sanders JL, Kent ML (2013) Verification of intraovum transmission of a microsporidium of vertebrates: Pseudoloma neurophilia infecting the zebrafish, Danio rerio. PLOS ONE 8:e76064

Schneider CA, Rasband WS, Eliceiri KM (2012) NIH Image to ImageJ: 25 years of image analysis. Nat Methods 9: 671-675

Sprague V (1977) Classification and phylogeny of the Microsporidia. In: Bulla LA, Cheng TC (eds) Comparative pathobiology. Springer, Boston, MA, p 1-30

* Sprengel G, Lüchtenberg H (1991) Infection by endoparasites reduces maximum swimming speed of European smelt Osmerus eperlanus and European eel Anguilla anguilla. Dis Aquat Org 11:31-35

* Stentiford GD, Becnel JJ, Weiss LM, Keeling PJ and others (2016) Microsporidia-emergent pathogens in the global food chain. Trends Parasitol 32:336-348

พ Tomamichel MM, Hodgins NC, Venturelli PA, Phelps NB (2018) The prevalence and potential fisheries consequences of Heterosporis sutherlandae in a Minnesota lake. PLOS ONE 13:e0199580

US Food and Drug Administration (2017) Food code. US Department of Health and Human Services, Public Health Service, Collge Park, MD. www.fda.gov/media/110822/ download (accessed 15 May 2020)

Weiss LM (2014) Clinical syndromes associated with microsporidiosis. In: Weiss LM, Becnel JJ (eds) Microsporidia: pathogens of opportunity. Wiley Blackwell, Ames, IA, p 371-402

Submitted: January 3, 2021

Accepted: March 2, 2021

Proofs received from author(s): May 21, 2021 